\title{
Targeting Risk Factors for the Control of Central Line- Associated Bloodstream Infection in the Neonatal Inten- sive Care Unit: A Single Tertiary Center Experience
}

Jiyoon Jeong, $\mathrm{MD}^{1, *}$, Yoojin Kwun, $\mathrm{MD}^{2, *}$, Min-ju Kim, $\mathrm{MSC}^{3}$, Sang-Ho Choi, $\mathrm{MD}, \mathrm{PhD}^{4}$, Euiseok Jung, $\mathrm{MD}^{1}$, Byong Sop Lee, $\mathrm{MD}, \mathrm{PhD}^{1}$, Ki-Soo Kim, MD, $\mathrm{PhD}^{1}$, and Ellen Ai-Rhan Kim, $\mathrm{MD}$, $\mathrm{PhD}^{1}$

${ }^{1}$ Division of Neonatology, Department of Pediatrics, Asan Medical Center Children's Hospital, University of Ulsan College of Medicine, Seoul, Korea

${ }^{2}$ Independent Researcher, Seoul, Korea

${ }^{3}$ Department of Clinical Epidemiology and Biostatistics, Asan Medical Center Clinical Research Center, Seoul, Korea

${ }^{4}$ Department of Infectious Diseases, Asan Medical Center, University of Ulsan College of Medicine, Seoul, Korea

\section{ABSTRACT}

Purpose: The aim of this study was to estimate the effect of targeting risk factors for the control of central line-associated bloodstream infection (CLABSI) among highrisk infants in a tertiary neonatal intensive care unit (NICU).

Methods: Infants admitted to the NICU and diagnosed with CLABSI from January to December 2013 were eligible for inclusion to the study. The CLABSI group $(n=47)$ was matched in a 1:2 ratio to the control group $(n=94)$ based on gestational age, birth weight, and Score for Neonatal Acute Physiology-II. Risk factors for CLABSI were identified using the Cox proportional hazard model, and analysis of the effect of these risk factors targeting infection control was performed.

Results: The risk factors associated with CLABSI were prolonged central line dwell days (adjusted hazard ratio [HR], 1.028; 95\% confidence interval [CI], 1.011 to 1.045; $P=0.001$ ), use of a silicone catheter (adjusted HR, 5.895; 95\% CI, 1.893 to 18.355; $P=$ 0.002), surgical treatment (adjusted HR, 3.793; 95\% CI, 1.467 to 9.805; $P=0.006$ ), and less probiotic supplementation (adjusted HR, $0.254 ; 95 \% \mathrm{CI}, 0.068$ to $0.949 ; P=0.042$ ). By targeting these risk factors with a quality improvement initiative, the mean CLABSI incidence rate per 1,000 catheter-days decreased from 6.6 to 3.1 ( $P=0.004)$.

Conclusion: Targeting risk factors for infection control significantly reduced the rate of CLABSI among high-risk infants in the NICU.

Key Words: Central venous catheter; Sepsis, neonatal; Risk factors; Neonatal intensive care unit; Quality improvement
Received: 26 May 2021

Revised: 17 June 2021

Accepted: 18 June 2021

Correspondence to: Ellen Ai-Rhan Kim, MD, PhD

Division of Neonatology, Department of Pediatrics, Asan Medical Center Child ren's Hospital, University of Ulsan College of Medicine, 88 Olympic-ro 43gil, Songpa-gu, Seoul 05505, Korea Tel: +82-2-3010-3382

Fax: +82-2-3010-6978

E-mail: arkim@amc.seoul.kr

*These authors contributed equally to this work.

Copyright(c)

By Korean Society of Neonatology.

This is an Open-Access article distributed under the terms of the Creative Commons Attribution Non-Commercial License (http:// creativecommons.org/licenses/by-nc/4.0), which permits unrestricted non-commercial use, distribution, and reproduction in any medium, provided the original work is properly cited. 


\section{INTRODUCTION}

A large proportion of high-risknewborns who require prolonged placement of a central catheter for parenteral nutrition are vulnerable to central line-associated bloodstream infection (CLABSI). CLABSI contributes $4 \%$ to $20 \%$ in mortality rate and increases patient length of stay by an average of 7 days, a significant increase in attributed cost ranging from $\$ 3,700$ to $\$ 29,000$ per infection in the United States ${ }^{1-3)}$. Therefore, finding practical and preventive measures to reduce CLABSI is one of the most important issues in the neonatal intensive care unit (NICU).

The reported risk factors associated with CLABSI include central venous catheter (CVC) dwell days of $\geq 21$ days, parenteral nutrition, prior CVC-associated bloodstream infection, underlying metabolic condition, non-operative cardiovascular disease, presence of a gastrostomy tube, and history of red blood cell trans fusion $^{4-7)}$. In addition, it is of note that intra-abdominal pathology or surgery also contributes to the increased risk of CLABSI in a tertiary NICU setting ${ }^{8)}$.

In our NICU, the CLABSI rate increased to 4.8 in 2012 and 6.6 in 2013 per device day. In this study, we aimed to determine the risk factors of CLABSI among high-risk infants and to determine the effect of risk factor-based infection control in reducing CLABSI.

\section{MATERIALS AND METHODS}

The eligibility criteria for inclusion during the study period from January 2013 to September 2014 were as follows: (1) newborns admitted to the NICU within 4 weeks of age or within 44 weeks of postmenstrual age, and (2) newborns with central catheterization, including umbilical catheters. Exclusion criteria were patients who were transferred to another center, general ward or pediatric intensive care unit immediately after cardiothoracic or abdominal surgery.

The general characteristics of the patient population and the risk factors associated with CLABSI were analyzed. The control group ( $n=94)$ was matched with the CLABSI group $(n=47)$ for gestational age ( \pm 1 weeks), birth weight $( \pm 500 \mathrm{~g})$, and Score for Neonatal Acute Physiology II (SNAP-II) severity ${ }^{9)}$ in a 1:2 ratio. The patients' SNAP-II were categorized as normal (0), mild (1$20)$, moderate (21-40), and severe ( $>40)$.

This study was divided into two phases. Phase I (January 2013 to January 2014) was a period of practicing universal precautions only. After analyzing the risk factors associated with CLABSI du ring phase I, a shift in infection control practice was started in phase II (February 2014 to September 2014), from practicing universal precautions only to initiating efforts to reduce or prevent targeted risk factors for infection control. The use of a silicone central catheter, probiotic supplementation, and prolonged central catheter dwelling time were identified as controllable risk factors for CLABSI. In order to reduce these risk factors, the use of polyurethane catheters and probiotic supplements (Lactobacil lus rhamnosus, Lactobacillus acidophilus [Lacidofil, Pharmbio Korea Co., Seoul, Korea]) was implemented for very low birth weight infants who reached full enteral feeding or at the discretion of the neonatologist. Central line insertion and maintenance bundles were also reinforced during phase II. Theoretical and practical education for house staff on hand hygiene, proper central line insertion, and dressing changes were provided. In addition, daily discussion regarding the necessity of central lines during attending physician rounds was conducted.

The diagnosis of CLABSI was made by our institution's infection control unit when the patient met the criteria of laboratoryconfirmed bloodstream infection (LCBI) with a central line or umbilical catheter in place for $\geq 2$ days. We used LCBI 3 criteria defined by the Centers for Disease Control and Prevention $\mathrm{Na}$ tional Healthcare Safety Network (CDC/NHSN) for the neonates admitted to our NICU who meet the following criteria ${ }^{10)}$. First, the infant should have at least one of the following clinical symptoms: fever $\left(>38^{\circ} \mathrm{C}\right.$ core temperature), hypothermia $\left(<36^{\circ} \mathrm{C}\right.$ core tem perature), apnea, or bradycardia. Second, positive laboratory results should not be related to infection at another site. Third, the same common organism was cultured from $\geq 2$ blood cultures drawn on separate occasions. The CLABSI incidence rate was calculated in two ways: number of CLABSIs per 1,000 catheterdays and number of CLABSIs per 1,000 patient-days. The central line utilization ratio is defined as the number of central line days per number of patient-days per year. If multiple episodes of CLABSI were encountered, only the first incidence of CLABSI was used for risk factor analysis. We defined early-onset sepsis as bacteremia occurring before 72 hours of life, and late-onset sepsis occurring after 72 hours of life. Surgical treatments and probiotic supplements were included only in cases prior to CLABSI.

We used a 28-gauge polyurethane catheter (Premicath, Vygon, Norristown, PA, USA), a polyurethane umbilical catheter (Human Catheter, Insung Medical Co., Wonju, Korea), and a 24-gauge silicone catheter (ECC, Vygon) for central line insertion during 
the study period. Central catheters were inserted under sterile conditions, including the use of sterile gowns, caps, and masks during catheter placement after skin disinfection with $2 \%$ chlorh exidine solution. The insertion site was covered with a transparent film dressing (Tegaderm, 3M Health Care, Neuss, Germany). Catheter hubs were cleaned with alcohol every time they were accessed.

SAS version 9.3 (SAS Institute Inc., Cary, NC, USA) and IBM SPSS Statistics version 20.0 (IBM Co., Armonk, NY, USA) were used for the analysis of the risk factors for CLABSI. Pre- and postinitiative patient populations were compared using the Student $t$-test or Wilcoxon rank sum test, where appropriate, for continuous variables, and the chi-square or Fisher exact test for categorical variables. Cox proportional hazard model with a sandwich variance estimate was used. The hazard ratio (HR) of CLABSI associated with the parameters was estimated in the range of $95 \%$ confidence interval (CI). Statistical significance was set at $P<0.05$.

\section{RESULTS}

Among 700 infants born in 2013 eligible for this study, 23 were transferred to other hospitals and were excluded. Of the 677 infants who fulfilled the inclusion criteria, 47 (6.94\%) were diag nosed with CLABSI. The control group was matched in a 1:2 ratio with the CLABSI group, resulting in a total of 94 neonates as control. Of the 141 infants, 61 (43.3\%) underwent surgical treat ment. The mean gestational age and birth weight were $31 \pm 5$ weeks and 1,444 $\pm 781 \mathrm{~g}$, respectively (Table 1). There was no

Table 1. Baseline Characteristics of the Study Groups

\begin{tabular}{lccc}
\hline Characteristic & Case $(\mathrm{n}=47)$ & Control $(\mathrm{n}=94)$ & $P$-value \\
\hline Gestational age (wk) & $30.11 \pm 5.19$ & $30.03 \pm 4.60$ & 0.885 \\
Birth weight (g) & $1,500.70 \pm 852.03$ & $1,416.21 \pm 746.13$ & 0.547 \\
SNAP-II & & & 0.827 \\
Normal (0) & $5(10.6)$ & $6(6.4)$ & \\
Mild (1-20) & $22(46.8)$ & $46(48.9)$ & \\
Moderate (21-40) & $12(25.5)$ & $27(28.7)$ & \\
Severe ( $\geq 41)$ & $8(17.0)$ & $15(16.0)$ & \\
Male sex & $22(46.8)$ & $46(48.9)$ & 0.812 \\
Apgar 1 min & $4.77 \pm 2.22$ & $5.48 \pm 2.27$ & 0.352 \\
Apgar 5 min & $6.45 \pm 2.19$ & $6.98 \pm 2.08$ & 0.726 \\
Intrauterine growth & $16(34.0)$ & $40(42.6)$ & 0.330 \\
restriction & & & \\
\hline
\end{tabular}

Values are expressed as mean \pm standard deviation or number (\%). Abbreviation: SNAP-II, Score for Neonatal Acute Physiology II. significant difference in the distribution of SNAP-II severity or other matching variables between the two groups. A total of 50 microorganisms were isolated from the CLABSI group; 40 (80\%) were gram-positive bacteria and $10(20 \%)$ were gram-negative bacteria. During the study period, the most common pathogens associated with CLABSIs were coagulase-negative staphylococci ( $\mathrm{n}=27,54 \%)$, followed by Staphylococcus aureus $(\mathrm{n}=8,16 \%)$, and Burkholderia cepacia ( $\mathrm{n}=6,12 \%)$ (Table 2). The mean onset of CLABSI was 37.1 days (range, 5 to 149) and all CLABSI episodes occurred after 72 hours of life.

Compared with the control group, the CLABSI group had a higher rate of silicone central catheter use, longer days of central catheter placement, longer days to achieve full enteral feeding, and longer duration of hospital stay. The CLABSI group used less probiotics than the control group during the NICU stay $(P=0.043)$

Table 2. Pathogens of Central Line-Associated Bloodstream Infections

\begin{tabular}{lc}
\hline Pathogen & No. $(\%)$ \\
\hline Coagulase negative staphylococci & $27(54)$ \\
Staphylococcus aureus & $8(16)$ \\
Burkholderia cepacia & $6(2)$ \\
Enterococcus spp. & $4(8)$ \\
Enterobacter spp. & $4(8)$ \\
Klebsiella spp. & $1(2)$
\end{tabular}

Table 3. Neonatal Morbidity and Infection-Related Parameters in the Study Groups

\begin{tabular}{|c|c|c|c|}
\hline Variable & $\begin{array}{l}\text { Case } \\
(n=47)\end{array}$ & $\begin{array}{c}\text { Control } \\
(n=94)\end{array}$ & $P$-value \\
\hline Respiratory distress syndrome & $35(74.5)$ & $70(74.5)$ & 1.000 \\
\hline Patent ductus arteriosus & $26(55.3)$ & $42(44.7)$ & 0.233 \\
\hline Necrotizing enterocolitis & $6(12.8)$ & $8(8.5)$ & 0.426 \\
\hline $\mathrm{IVH} \geq$ grade 3 & $11(23.4)$ & $12(12.8)$ & 0.107 \\
\hline All surgical treatment & $28(59.6)$ & $33(35.1)$ & 0.006 \\
\hline Major surgery* & $27(57.4)$ & $32(34.0)$ & 0.008 \\
\hline Probiotics & $4(8.5)$ & $21(22.3)$ & 0.043 \\
\hline C-line, silicone & $38(80.9)$ & $57(60.6)$ & 0.016 \\
\hline C-line, polyurethane & $9(19.1)$ & $37(39.4)$ & 0.016 \\
\hline C-line days & $52.23 \pm 39.99$ & $33.63 \pm 25.23$ & 0.005 \\
\hline Days to full feeding & $53.07 \pm 35.75$ & $37.53 \pm 26.46$ & 0.016 \\
\hline Length of hospital stay (d) & $83.74 \pm 46.18$ & $64.77 \pm 42.73$ & 0.017 \\
\hline
\end{tabular}


Table 4. Change in Clinical Practices between Phase I and Phase II

\begin{tabular}{lccc}
\hline Variable & Phase I (Jan 2013-Jan 2014) & Phase II (Feb 2014-Sep 2014) & $P$-value \\
\hline No. of patients admitted to NICU & 815 & 721 & 19 \\
No. of CLABSI events & 56 & $231(32.0)$ \\
No. of patients with central line & $326(40.0)$ & 6,158 & 3.1 \\
Total central line dwell (d) & 8,543 & 8,955 & 0.001 \\
Mean CLABSI incidence rate (/1,000 catheter-d) & 6.6 & 2.1 & 0.004 \\
Patient (d) & 15,130 & $194(84.0)$ & 0.033 \\
Mean CLABSI incidence rate per (/1,000 patient-d) & 3.7 & $37(16.0)$ & $<0.001$ \\
Mean central line utilization ratio & 0.56 & $45(19.5)$ & $<0.001$ \\
Central catheter, silicone & $313(96.0)$ & $13(4.0)$ & 0.026 \\
Central catheter, polyurethane & $41(12.6)$ & & \\
No. of probiotics* usage among patients with C-line & &
\end{tabular}

Values are expressed as number (\%)

*Only for Lactobacillus rhamnosus and Lactobacillus acidophilus.

Abbreviations: NICU, neonatal intensive care unit; CLABSI, central line associated bloodstream infection.

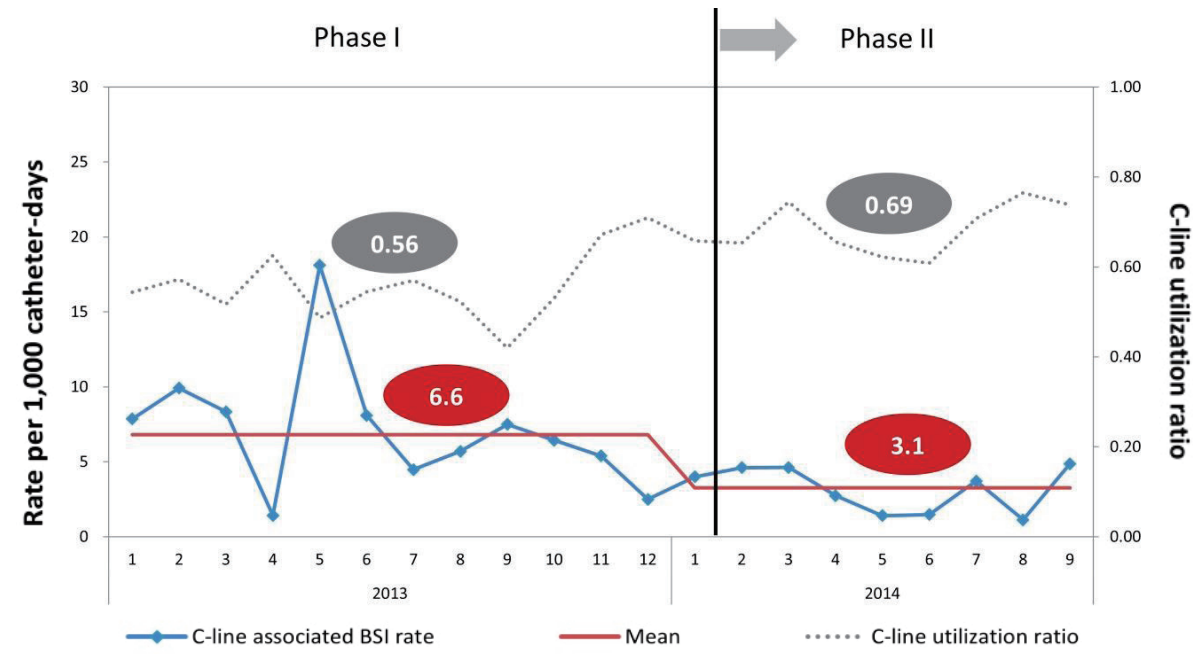

Figure 1. Incidence of central line-associated bloodstream infection and central line utilization ratio between phase I and phase II.

(Table 3). The incidence of all surgical treatments and major surgeries was higher in the CLABSI group than in the control group.

The risk factor analysis for CLABSI using the Cox proportional hazard model with sandwich variance estimate is shown in Table 3. Univariate model analysis showed that the use of a silicone central catheter, probiotic supplementation, prolonged central catheter dwelling time, history of surgical treatment and major surgery, and prolonged time to achieve full enteral feeding were significantly associated with CLABSI. After adjusting for confounding factors, the HR of CLABSI significantly decreased with shorter duration of central line placement, usage of polyurethane catheter, and probiotic supplementation (Table 4).

The changes in clinical infection control practices focusing on risk factors between phases I and II are shown in Table 5. The mean CLABSI incidence rate per 1,000 catheter-days decreased from 6.6 to 3.1 despite increased central line utilization ratio from 0.56 to 0.69 ( $P=0.004$ ) (Figure 1). The usage of polyurethane catheters increased from $4.0 \%$ to $16.0 \%$, and probiotic use increased from $12.6 \%$ to $19.5 \%$ during phase II.

\section{DISCUSSION}

The basic neonatal characteristics, specifically sex, intrauterine growth restriction, respiratory distress syndrome, patent ductus arteriosus, and intraventricular hemorrhage, did not have a 
Table 5. Central Line-Associated Bloodstream Infection Risk Factor Analysis by Cox Proportional Hazard Model with Sandwich Variance Estimate

\begin{tabular}{|c|c|c|c|c|}
\hline \multirow{2}{*}{ Variable } & \multicolumn{2}{|l|}{ Univariate model } & \multicolumn{2}{|c|}{ Multivariate model } \\
\hline & Unadjusted HR (95\% CI) & $P$-value & Adjusted HR (95\% CI) & $P$-value \\
\hline Sex (male vs. female) & $0.891(0.352-2.257)$ & 0.808 & & \\
\hline Intrauterine growth restriction & $0.928(0.274-3.145)$ & 0.904 & & \\
\hline RDS & $1.000(0.448-2.232)$ & 1.000 & & \\
\hline PDA & $1.533(0.758-3.100)$ & 0.235 & & \\
\hline NEC $\geq$ stage 2 & $1.573(0.512-4.831)$ & 0.429 & & \\
\hline $\mathrm{IVH} \geq$ grade 3 & $2.925(0.771-11.091)$ & 0.115 & & \\
\hline All surgical treatment & $2.724(1.326-5.598)$ & 0.006 & $3.793(1.467-9.805)$ & 0.006 \\
\hline Major surgery* & $2.616(1.275-5.366)$ & 0.009 & $4.160(1.447-11.958)$ & 0.008 \\
\hline C-line days & $1.018(1.007-1.030)$ & 0.002 & $1.028(1.011-1.045)$ & 0.001 \\
\hline Days to full feeding & $1.016(1.004-1.029)$ & 0.010 & & \\
\hline Probiotics & $0.150(0.031-0.711)$ & 0.017 & $0.254(0.068-0.949)$ & 0.042 \\
\hline C-line, silicone & $9.983(2.342-42.555)$ & 0.002 & $5.895(1.893-18.355)$ & 0.002 \\
\hline C-line, polyurethane & $0.100(0.023-0.427)$ & 0.002 & $0.170(0.054-0.528)$ & 0.002 \\
\hline
\end{tabular}

*Major surgery included laparotomy, thoracotomy, neurosurgery, and open urologic surgery.

Abbreviations: HR, hazard ratio; CI, confidence interval; RDS, respiratory distress syndrome; PDA, patent ductus arteriosus; NEC, necrotizing enterocolitis; IVH, intraventricular hemorrhage; C-line, central line.

statistically significant effect on the occurrence of CLABSI when confounding factors were adjusted using the Cox proportional hazard model, as in other reports ${ }^{4)}$. The SNAP-II was used in our study as a matching variable to compare the effects of prognostic severity. Although SNAP-II severity has been used to predict the propensity towards mortality among preterm infants under gestational age of 35 weeks, it has also been used for term, as well as late term infants ${ }^{11)}$. In our study, the CLABSI group showed a higher proportion of surgical treatment $(P=0.006)$. As a tertiary NICU, the proportion of patients who needed surgical treatment, including pediatric surgery, neurosurgery, cardiothoracic surgery, urologic surgery, and otorhinolaryngologic surgery, was higher (43.3\%) than in other Korean NICUs ${ }^{12)}$. The reason why surgery is associated with an increased occurrence of CLABSI is unclear. A proportion of CLABSI is caused by enteric pathogens, which can colonize the skin and the CVC, with or without surgical manipulation that breaks bowel wall integrity ${ }^{13)}$. Prolonged exposure to parenteral nutrition is another risk factor related to recent surgery or associated to poor medical conditions that hinder the advancement of enteral feeding.

Our study suggests that targeting either the introduction of beneficial factors or avoidance of individual risk factors in each center would facilitate more effective infection control in combating CLABSI. For example, the average aggregate CLABSI rate decreased significantly with increased use of polyurethane central catheters $^{14)}$ and probiotics ${ }^{15)}$.

Many studies have suggested that the longer the central catheter dwell time, the greater the risk of catheter complications, including CLABSIs ${ }^{16-19)}$. A multicenter study showed that the risk of CLABSI increased during the first 2 weeks after CVC insertion and remained elevated until CVC removal ${ }^{20)}$. Prolonged catheter dwell times also showed higher CLABSI risk in our study; however, the association was weak, with an HR of 1.028. This is believed to be due to the finding that the study participants showed relatively long central catheter dwell times $(52.23 \pm 39.99$ days vs. $33.63 \pm$ 25.23 days, $P=0.005)$. Since most of the central catheters are routinely used in high-risk infants to provide access for prolonged intravenous medication and parenteral nutrition in the $\mathrm{NICU}^{21)}$, promoting enteral feeding could reduce the risk of CLABSI while shortening the central catheter dwell time.

Use of a polyurethane central catheter was also identified as a factor that reduced CLABSI in this study. Silicone and polyurethane CVC lines were associated with different types of complications due to their physical properties, such as tensile strength, resistance, and flow rate ${ }^{14,22)}$. The superiority of the polyurethane catheter to the silicone catheter was not consistent across studies. In a retrospective analysis of adult patients, the rates of CLABSI and thrombotic complications were more frequently associated with polyurethane catheters than with silicone catheters ${ }^{23)}$. Conversely, silicone catheters were associated with higher rates of 
CLABSI $^{14)}$ and colonization among newborn infants ${ }^{24)}$. Silicone is a soft material that is flexible and easy to insert into the vein of an infant with reduced vein trauma. However, because of its flexibility, the wall of the catheter must be thick to achieve catheter resistance. Since this leads to a decrease in flow rate, it may result in a higher occlusion rate and catheter rupture. Polyurethane is a stiff material, which results in increased catheter resistance and an increased flow rate due to the thinner wall of the catheter ${ }^{25)}$. How ever, some studies suggest a greater incidence of pericardial and pleural effusion with polyurethane catheters than with silicone catheters $^{26)}$.

The rationale for probiotic supplementation is to normalize the gut microbiome with exogenous microorganisms, increasing the resistance of the intestinal mucosal barrier to prevent the trans location of bacteria, modifying the host response to microbial products, and enhancing enteral nutrition and gut maturation ${ }^{15,27)}$. Although theoretically promising, the use of probiotics in clinical trials has revealed inconsistent results with regard to the preven tion of sepsis in this vulnerable population, and meta-analyses have shown that probiotics did not significantly reduce the incidence of sepsis ${ }^{27,28)}$. In contrast, a Cochrane review confirmed that probiotic supplementation significantly reduced the incidence of necrotizing enterocolitis and mortality ${ }^{29)}$. Meta-analyses have shown that probiotic supplementation reduces the time to full enteral feeding ${ }^{30)}$ and sepsis ${ }^{31)}$ in preterm neonates. Probiotics may reduce the CLABSI rate either by having a direct beneficial effect on the immune system or by reducing the requirement for central line placement by accelerating the time to reach full enteral nutrition. However, safety concerns remain regarding adverse effects such as probiotics-associated bloodstream infections in immunocompromised hosts with $\mathrm{CVCs}^{32-34)}$. Further large-scale studies are required to confirm the efficacy of pro biotics in CLABSI prevention.

Several considerations should be taken when interpreting our findings. First, as a single-center study showing a high surgical treatment rate and severity score, the device utilization ratio and CLABSI rate itself were higher than those in previous reports ${ }^{35)}$. Moreover, decreasing the number of surgical interventions is a difficult task to control, which requires extensive analysis. Second, due to the limitations of the case-control study design, the high incidence of surgical cases and the frequent usage of probiotics might have been a matter of selection bias. Moreover, as central line insertion practices have changed over time, our findings should be confirmed with more recent data.
In conclusion, central catheters are essential for the care of hospitalized infants, and prevention of CLABSI is important to improve outcomes in the NICU population. Additive efforts to target risk factors showed improvements in reducing CLABSI among high-risk infants in the NICU.

\section{ARTICLE INFORMATION}

\section{Ethical statement}

The Institutional Review Board of the Asan Medical Center ap proved the study (IRB No. 2015-0100). Informed written consent was waived due to the retrospective design of the study.

\section{Conflicts of interest}

No potential conflict of interest relevant to this article was reported.

\section{Author contributions}

Conception or design: E.A.R.K.

Acquisition, analysis, or interpretation of data: J.J., Y.K., M.K., S.H.C.

Drafting the work or revising: J.J., Y.K., E.J., B.S.L., E.A.R.K.

Final approval of the manuscript: J.J., Y.K., S.H.C., E.J., B.S.L., K.S.K., E.A.R.K.

\section{ORCID}

Jiyoon Jeong https://orcid.org/0000-0002-3363-1162

Yoojin Kwun https://orcid.org/0000-0001-6252-772X

Ellen Ai-Rhan Kim https://orcid.org/0000-0002-9859-3021

\section{Acknowledgments}

None

\section{REFERENCES}

1. Saint S, Veenstra DL, Lipsky BA. The clinical and economic con sequences of nosocomial central venous catheter-related infection: are antimicrobial catheters useful? Infect Control Hosp Epidemiol 2000;21:375-80.

2. Payne NR, Carpenter JH, Badger GJ, Horbar JD, Rogowski J. Marginal increase in cost and excess length of stay associated with nosocomial bloodstream infections in surviving very low birth weight infants. Pediatrics 2004;114:348-55. 
3. Yoo S, Jung SI, Kim GS, Lim DS, Sohn JW, Kim JY, et al. Interventions to prevent catheter-associated blood-stream infections: a multicenter study in Korea. Infect Chemother 2010;42:216-22.

4. Wylie MC, Graham DA, Potter-Bynoe G, Kleinman ME, Randolph AG, Costello JM, et al. Risk factors for central line-associated bloodstream infection in pediatric intensive care units. Infect Control Hosp Epidemiol 2010;31:1049-56.

5. O'Grady NP, Alexander M, Burns LA, Dellinger EP, Garland J, Heard SO, et al. Guidelines for the prevention of intravascular catheter-related infections. Clin Infect Dis 2011;52:e162-93.

6. Mannan K, Chow P, Lissauer T, Godambe S. Mistaken identity of skin cleansing solution leading to extensive chemical burns in an extremely preterm infant. Acta Paediatr 2007;96:1536-7.

7. Horbar JD, Plsek PE, Leahy K; NIC/Q 2000. NIC/Q 2000: establishing habits for improvement in neonatal intensive care units. Pediatrics 2003;111(4 Pt 2):e397-410.

8. Dahan M, O'Donnell S, Hebert J, Gonzales M, Lee B, Chandran AU, et al. CLABSI risk factors in the NICU: potential for prevention: a PICNIC study. Infect Control Hosp Epidemiol 2016;37: 1446-52.

9. Richardson DK, Corcoran JD, Escobar GJ, Lee SK. SNAP-II and SNAPPE-II: simplified newborn illness severity and mortality risk scores. J Pediatr 2001;138:92-100.

10. Liang SY, Marschall J. Update on emerging infections: news from the Centers for Disease Control and Prevention. Vital signs: central line-associated blood stream infections: United States, 2001, 2008, and 2009. Ann Emerg Med 2011;58:447-51.

11. Coleman AJ, Brozanski B, Mahmood B, Wearden PD, Potoka D, Kuch BA. First 24-h SNAP-II score and highest $\mathrm{PaCO} 2$ predict the need for ECMO in congenital diaphragmatic hernia. J Pediatr Surg 2013;48:2214-8.

12. Sung SI, Lee NH, Kim HH, Kim HS, Han YS, Yang M, et al. The impact of surgical intervention on neurodevelopmental outcomes in very low birth weight infants: a nationwide cohort study in Korea. J Korean Med Sci 2019;34:e271.

13. Polin RA, Denson S, Brady MT; Committee on Fetus and Newborn; Committee on Infectious Diseases. Epidemiology and diagnosis of health care-associated infections in the NICU. Pe diatrics 2012;129:e1104-9.

14. Seckold T, Walker S, Dwyer T. A comparison of silicone and polyurethane PICC lines and postinsertion complication rates: a systematic review. J Vasc Access 2015;16:167-77.

15. Garland SM, Tobin JM, Pirotta M, Tabrizi SN, Opie G, Donath S, et al. The ProPrems trial: investigating the effects of probiotics on late onset sepsis in very preterm infants. BMC Infect Dis 2011; $11: 210$.

16. Jumani K, Advani S, Reich NG, Gosey L, Milstone AM. Risk factors for peripherally inserted central venous catheter complications in children. JAMA Pediatr 2013;167:429-35.

17. Sengupta A, Lehmann C, Diener-West M, Perl TM, Milstone AM.
Catheter duration and risk of CLA-BSI in neonates with PICCs. Pediatrics 2010;125:648-53.

18. Ohki Y, Maruyama K, Harigaya A, Kohno M, Arakawa H. Com plications of peripherally inserted central venous catheter in Japanese neonatal intensive care units. Pediatr Int 2013;55:1859.

19. Milstone AM, Sengupta A. Do prolonged peripherally inserted central venous catheter dwell times increase the risk of blood stream infection? Infect Control Hosp Epidemiol 2010;31:11847.

20. Milstone AM, Reich NG, Advani S, Yuan G, Bryant K, Coffin SE, et al. Catheter dwell time and CLABSIs in neonates with PICCs: a multicenter cohort study. Pediatrics 2013;132:e1609-15.

21. Ainsworth SB, McGuire W. Peripherally inserted central catheters vs peripheral cannulas for delivering parenteral nutrition in neonates. JAMA 2016;315:2612-3.

22. de Lutio E. Which material and device? The choice of PICC. In: Sandrucci S, Mussa B. Peripherally inserted central venous catheters. Milan: Springer, 2014:7-19.

23. Wildgruber M, Lueg C, Borgmeyer S, Karimov I, Braun U, Kiechle $\mathrm{M}$, et al. Polyurethane versus silicone catheters for central venous port devices implanted at the forearm. Eur J Cancer 2016; 59:113-24.

24. Rudin C, Nars PW. A comparative study of two different percutaneous venous catheters in newborn infants. Eur J Pediatr 1990; 150:119-24.

25. SmirkC, Soosay Raj T, Smith AL, Morris S. Neonatal percutaneous central venous lines: fit to burst. Arch Dis Child Fetal Neonatal Ed 2009;94:F298-300.

26. Pezzati M, Filippi L, Chiti G, Dani C, Rossi S, Bertini G, et al. Central venous catheters and cardiac tamponade in preterm infants. Intensive Care Med 2004;30:2253-6.

27. Nair V, Soraisham AS. Probiotics and prebiotics: role in preven tion of nosocomial sepsis in preterm infants. Int J Pediatr 2013; 2013:874726.

28. Jacobs SE, Tobin JM, Opie GF, Donath S, Tabrizi SN, Pirotta M, et al. Probiotic effects on late-onset sepsis in very preterm infants: a randomized controlled trial. Pediatrics 2013;132:1055-62.

29. Sharif S, Meader N, Oddie SJ, Rojas-Reyes MX, McGuire W. Probiotics to prevent necrotising enterocolitis in very preterm or very low birth weight infants. Cochrane Database Syst Rev 2020; 10:CD005496.

30. Athalye-Jape G, Deshpande G, Rao S, Patole S. Benefits of pro biotics on enteral nutrition in preterm neonates: a systematic review. Am J Clin Nutr 2014;100:1508-19.

31. Rao SC, Athalye-Jape GK, Deshpande GC, Simmer KN, Patole SK. Probiotic supplementation and late-onset sepsis in preterm infants: a meta-analysis. Pediatrics 2016;137:e20153684.

32. Koh JY, Seo E, Lee J. A retrospective analysis of characteristics of probiotics associated with invasive bacterial infections in child- 
ren. Pediatr Infect Vaccine 2017;24:168-77.

33. Zbinden A, Zbinden R, Berger C, Arlettaz R. Case series of Bifidobacterium longum bacteremia in three preterm infants on pro biotic therapy. Neonatology 2015;107:56-9.

34. Kim SY, Woo HK, Kim EK, JungYH, Koh J, Song IG, etal. Influence of routine probiotic supplementation on the incidence of ne crotizing enterocolitis and late onset sepsis. Neonatal Med 2016; 23:88-94.

35. Dudeck MA, Edwards JR, Allen-Bridson K, Gross C, Malpiedi PJ, Peterson KD, et al. National Healthcare Safety Network report, data summary for 2013, device-associated module. Am J Infect Control 2015;43:206-21. 